\title{
A case study on the influence of THM coupling on the near field safety of a spent fuel repository in sparsely fractured granite
}

\author{
Thanh Son Nguyen ${ }^{1 *}$, Lennart Börgesson ${ }^{2}$, Masakazu Chijimatsu ${ }^{3}$, Jan Hernelind ${ }^{4}$, \\ Lanru Jing $^{5}$, Akira Kobayashi ${ }^{6}$, Jonny Rutqvist ${ }^{7}$ \\ ${ }^{1}$ Canadian Nuclear Safety Commission, Ottawa, Canada \\ ${ }^{2}$ Clay Technology AB, Lund, Sweden \\ ${ }^{3}$ Hazama Cooperation, Tokyo, Japan \\ ${ }^{4}$ FEM Tech AB, Sweden \\ ${ }^{5}$ Royal Institute of Technology, Stockholm, Sweden \\ ${ }^{6}$ Kyoto University, Kyoto, Japan \\ ${ }^{7}$ Earth Sciences Division, Lawrence Berkeley National Laboratory, Berkeley, CA 94720, USA
}

DECOVALEX-THMC 


\section{Abstract}

In order to demonstrate the feasibility of geological disposal of spent CANDU fuel in Canada, a safety assessment was performed for a hypothetical repository in the Canadian Shield. The assessment shows that such repository would meet international criteria for dose rate; however, uncertainties in the assumed evolution of the repository were identified. Such uncertainties could be resolved by the consideration of coupled Thermal-Hydro-Mechanical-Chemical (THMC) processes. In Task A of the DECOVALEXTHMC project, THM models were developed within the framework of the theory of poroelasticity. Such model development was performed in an iterative manner, using experimental data from laboratory and field tests. The models were used to perform near-field simulations of the evolution of the repository in order to address the above uncertainties. This paper presents the definition and rationale of task A and the results of the simulations. From a repository safety point of view, the simulations predict that the maximum temperature would be well below the design target of $100{ }^{\circ} \mathrm{C}$, however the load on the container can marginally exceed the design value of $15 \mathrm{MPa}$. However, the most important finding from the simulations is that a rock damage zone could form around the emplacement borehole. Such damage zone can extend a few metres from the walls of the emplacement holes, with permeability values that are orders of magnitude higher than the initial values. The damage zone has the potential to increase the radionuclide transport flux from the geosphere; the effect of such an increase should be taken into account in the safety assessment and mitigated if necessary by the provision of sealing systems.

\section{Keywords:}

coupled processes, excavation disturbed zone, damage, permeability, TSX 


\section{Introduction}

Geological disposal of nuclear fuel wastes relies on the concept of a multi-barrier system that minimizes the transfer of contaminants from the wastes to the biosphere. The proponents for geological disposal must provide adequate assurance that this multi-barrier system would provide protection for humans and the environment for at least thousands of years. The integration of arguments to support the long term safety of the repository is called a safety case (Nuclear Energy Agency, 2004). Central to a safety case is a safety assessment (SA). A safety assessment involves the understanding of the processes responsible for and influencing the release of contaminants, the development of mathematical models and their use to calculate the impact of these releases to humans and the environment. Usually, the main tool used in a safety assessment is an integrated system model that should be able to capture all significant features, events and processes in the engineered barriers, geosphere and biosphere. It is neither practical nor necessary to include all processes or their interactions in a system model. Simplifications can be made if they are shown to be conservative or if a higher degree of complexity is shown to not significantly influence the end results. In order to justify the simplifications in the SA, the analyst has to interact with geoscientists and engineers specialized in different disciplines. Barriers do exist between areas of specialty, and difference in terminology alone could be one of these barriers. In order to obtain a consistent understanding of the present and future behaviour of the repository, it is recognized that there is a need of communication and integration between experts in different disciplines (NEA, 2005), especially since many physical and chemical processes are coupled. As an example, the hydrogeologist should know that the flow field is influenced by the mechanical regime and vice versa. During the last 17 years, the international 
DECOVALEX project has strived to provide cooperation between experts in multiple geoscientific disciplines in order to develop mathematical models for coupled THMC processes. The models developed within DECOVALEX have been extensively verified and validated using both laboratory and field experiments. It is believed that several safety features of a repository might be overlooked without the considerations of coupled processes (Chijimatsu et al. 2005); it is also believed that coupled THMC models can now be confidently used to provide bounding parameters and confirm the simplifying assumptions used in SA models.

Gierszewski et al. (2003) and Garisto et al. (2005) performed a safety assessment of a hypothetical repository for spent CANDU fuel in the Canadian Shield, for respectively, an inroom emplacement and a horizontal borehole concept. The assessment was based on information typical of that available during the site investigation stage but prior to exploratory drilling. The results of the SA show that the hypothetical repository would meet international guidelines for dose rate, and if the site were a real candidate site, there is technical support to proceed to exploratory drilling. The above SA does not consider the implications of THMC coupling, and it is recognized (McMurry et al. 2003) that many aspects related to THMC coupling should be resolved in order to reduce uncertainties in the SA results. Task A of DECOVALEX-THMC specifically addresses the last point. The present paper provides the definition and rationale of Task A, the results of THM analyses of the near field of the repository and their implications on the safety of the hypothetical repository. Four teams are involved in the task to its completion: the Canadian Nuclear Safety Commission (CNSC); Clay Technologies supported by the Swedish Nuclear Fuel and Waste Management Corporation (SKB); Lawrence Berkeley National Laboratories supported by the Swedish Nuclear Power Inspectorate (SKI); and HAZAMA Corporation supported by the Japan Atomic Energy Agency (JAEA). 


\section{Repository description}

The repository being considered is based on one of the several Canadian case studies. It would be constructed at a nominal depth of $650 \mathrm{~m}$ in a stable crystalline rock of the Canadian Shield (Fig. 1) and would consist of a network of horizontal access galleries and emplacement rooms. Several methods of waste emplacement are considered. In this work, we will look at a horizontal borehole emplacement method, where the waste containers are emplaced in horizontal rooms, and the gaps between the rock and the containers will be filled with a bentonite buffer material. Rock masses of the Canadian Shield typically contain very few fractures outside of the major fracture zones (at depth). For the hypothetical repository and site, the assumed fracture zones in the vicinity of the repository are shown in Figure 1 . The repository relies on a multiple-barrier system in order to ensure the long term safety of people and the environment. These are the engineered barriers and the geosphere.

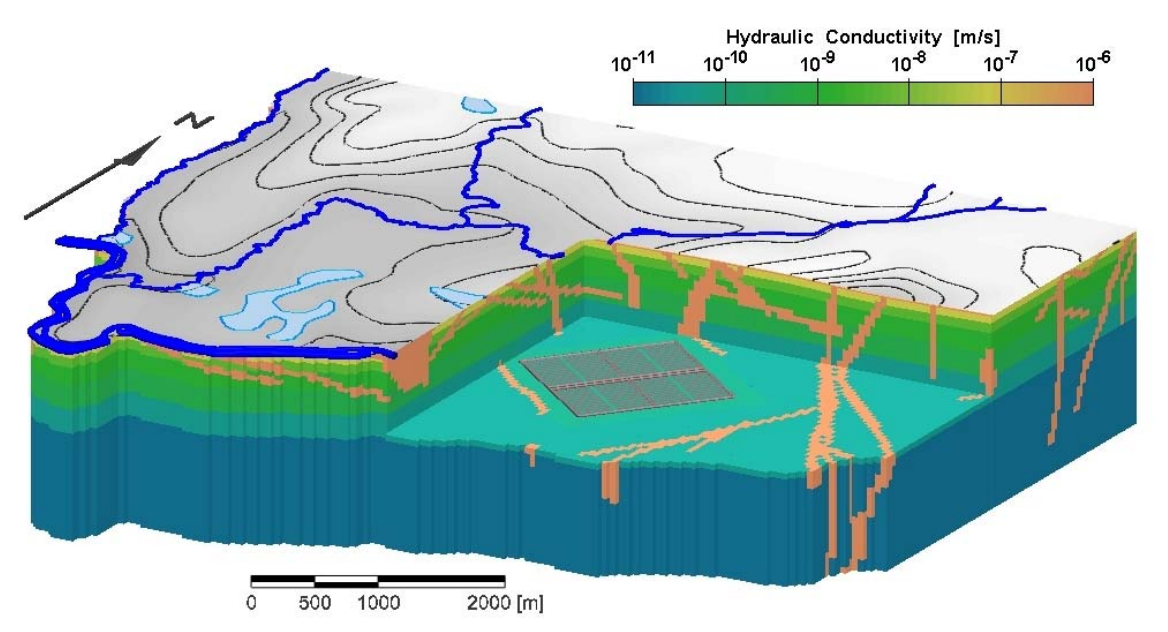


a) Overall view ((from McMurry et al. 2003)

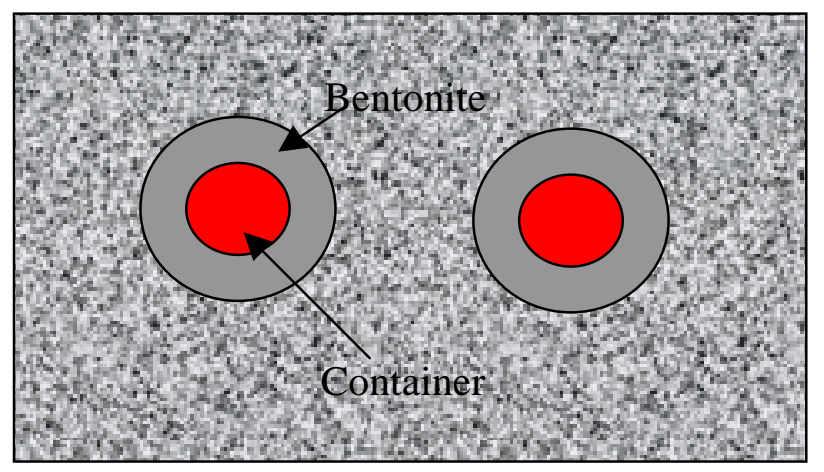

b) Typical horizontal emplacement boreholes

Figure 1. Repository layout

\section{The engineered barriers}

The engineered barriers are the waste form, the container and the buffer.

The waste form: CANDU reactors in Canada are fuelled by ceramic pellets of natural Uranium dioxide. These pellets are placed inside Zircaloy-4 fuel sheaths, closed by a welded zirconium alloy plug at the end. Each loaded and closed fuel sheath forms a fuel element. The fuel elements are in turn welded together to form a fuel bundle. This hypothetical repository would contain 3.6 million bundles of used CANDU fuel. At emplacement, the used fuel bundles would have a minimum age of 30 years after the reactor discharge.

The container (Fig. 3): The container being considered is similar to the Swedish and Finnish containers. It would encapsulate 324 fuel bundles in 6 layers, and have a total mass of $23.5 \mathrm{Mg}$. A 25 - 30 mm thick outer copper shell will provide a corrosion barrier. The structural resistance 
is provided by an $80-100 \mathrm{~mm}$ thick inner steel shell, designed to withstand a pressure of $15 \mathrm{MPa}$ (from hydrostatic pressure and swelling pressure from the buffer), plus an additional $30 \mathrm{MPa}$ from future glaciations. The maximum design temperature for the exterior surface of the container is $100^{\circ} \mathrm{C}$.

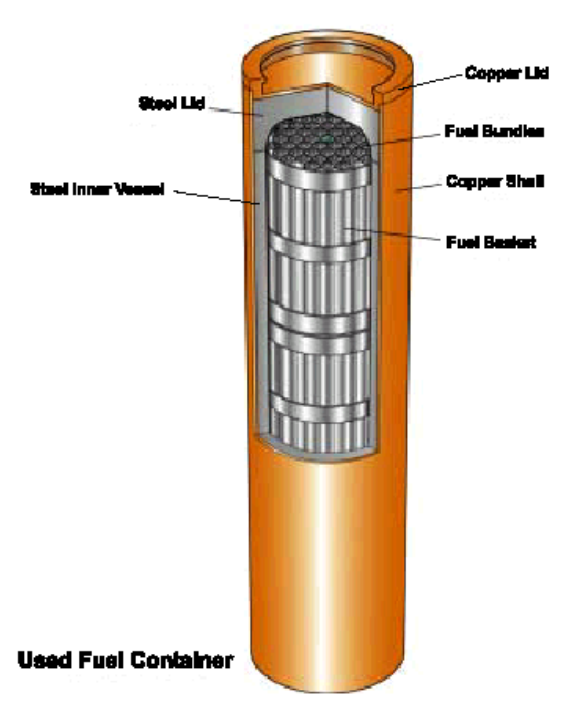

Figure 2. $\quad$ Canadian Used Fuel container (McMurry et al. 2003)

The buffer: The buffer is a bentonite-based clay material. The main mineral responsible for swelling property of the buffer is montmorillonite. Upon saturation, the bentonite expands to several times from its original volume if unrestrained; under confinement, a swelling pressure would develop. The main functions of the buffer are:

- To limit the corrosion rate of the container by inhibiting the movement and modifying the chemistry of the groundwater

- To conduct heat away from the container

- To keep the container in place

- To provide a mechanical buffer between the container and the rock 
- To reduce the potential for microbial activity.

- To ensure diffusion-controlled conditions and provide surface area, to retard any released radionuclides.

\subsection{The geosphere}

The geosphere is a plutonic rock mass of the Canadian Shield. The Canadian Shield is formed by large bodies of igneous rock called plutons that crystallized more than 2 billion years ago from magma. The topography of the Shield is flat, therefore, the hydraulic gradients are small (of the order of $0.1 \%$ ) The main functions of the geosphere are to:

- Protect the repository from natural events (such as earthquakes and glaciations) and human intrusion.

- Limit the rate of contaminant transport to the biosphere.

In-situ stress at different locations of the Shield has been compiled by Herget and Arjang (1990). In general, the minor principal stress is vertical and results from the weight of the overburden, while the major principal stress is sub-horizontal, is oriented NE to E, and could be higher than the vertical stress by a factor of three. In general, the degree of fracturing in a typical plutonic rock mass of the Canadian Shield generally decreases with depth, while the in-situ stresses increase. Consequently, there is a general decrease in the permeability with depths as shown in Figure 3. In the top 200-300 m, the permeability varies in a range from $10^{-18}$ to $10^{-3} \mathrm{~m}^{2}$. At depths of $500 \mathrm{~m}$, permeability values are in a range of $10^{-18}$ to $10^{-20} \mathrm{~m}^{2}$, while at depths greater than $1000 \mathrm{~m}$, the rock is essentially intact with permeability lower than $10^{-21} \mathrm{~m}^{2}$. This type of permeability distribution has a profound influence on the nature and chemical-physical properties of the groundwater. At depths less than $300 \mathrm{~m}$, one finds shallow, advective 
groundwater zones with low salinity, showing significant interaction with infiltrating waters from the surface. At greater depths, stagnant zones of groundwater, whose age is in the order of millions years, are found. The high salinity of these deep waters results in a higher relative density, up to 1.1 as compared to fresh water.

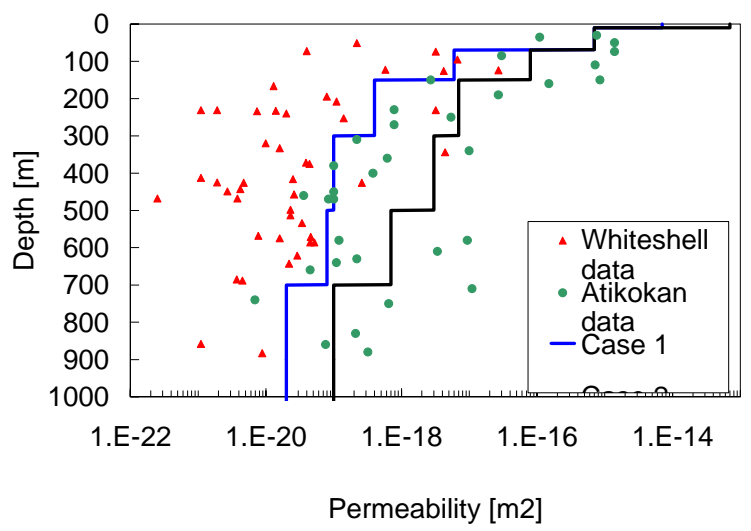

Figure 3. Permeability distribution with depth - data from Canadian Shield (from McMurry et al. 2003)

\subsection{Evolution of repository: base scenario}

McMurry et al. (2003) have defined a base scenario that was then used by the SA analysts (Gierszewski et al, 2003; Garisto et al, 2005) to conduct a performance assessment of the repository. The base scenario was derived by a combination of mathematical modelling of detailed processes and expert opinions. Under this base scenario, the anticipated evolution of the repository would be as follows:

$\underline{\mathbf{0 - 1 0 0} \text { years: }}$ During this time period, the repository would be open and actively monitored. Approximately 11,000 containers of used fuel would be emplaced and filled up rooms would be progressively sealed during a 30-year operational period, covering an area of $1.6 \mathrm{~km}^{2}$. The operational period would be followed by 70 years of monitoring when the access tunnels would 
be kept open. The initial thermal ouput from the repository is $13 \mathrm{MW}$, and the initial radioactivity is $10^{20} \mathrm{~Bq}$. During this time period, it is expected that:

- The thermal output would decrease by a factor of four and radioactivity drops by a factor of ten, at 100 years.

- The peak temperature on the outer surface of the containers is less than $100{ }^{\circ} \mathrm{C}$.

- The bentonite near the container dries out and desiccates. Bacterial activity is minimal or even non-existent due to heat, desiccation, lack of water and nutrients.

- The copper container surface reacts with oxygen to form a thin corrosion layer. Localized corrosion processes are not possible due to lack of water and microbes.

- At 100 years, the thermal plume would extend approximately $100 \mathrm{~m}$ around the repository

- Microcracking occurs in the rock around the opening due to excavation and possibly thermal stresses. This results in a change in the permeability and mechanical properties of the rock.

- The rock has to supply water to the unsaturated bentonite, resulting in an inward gradient. This is countered by the thermally generated pore pressure increase that creates an outward gradient.

100-1000 years: At the beginning of this period, all access shafts and tunnels would be closed. There would be high physical, chemical and biological gradients between the different components of the repository, and between the repository and the geosphere. These gradients are the driving forces for the evolution of the repository/geosphere system. It is expected that during that period: 
- The radioactivity drops by a further factor of 30 ; the thermal output drops to $1.3 \mathrm{MW}$

- The bentonite and seals are expected to be fully saturated by the end of this period. As water enters the bentonite, swelling pressures start to develop and would be transmitted to the container. After full resaturation, the full hydrostatic pressure would also be transmitted to the container. Under these loads, the copper shell would compress into the steel shell, which is expected to retain its shape and integrity. With the presence of water, pit corrosion would start at specific locations of the container surface; however, the penetration depths are expected to be less than several mm.

- At 1000 years, the thermal plume would extend a few hundred metres around the repository.

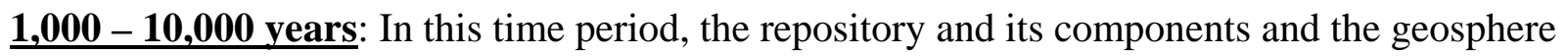
gradually reach an equilibrium state. It is expected that:

- Radioactivity drops by a further factor of two. Thermal output from the repository drops to approximately $0.5 \mathrm{MW}$. The thermal plume reaches its largest extent of a few hundreds of metres in all direction. However the temperature has dropped to maximum values between $30-60^{\circ} \mathrm{C}$.

- Since all oxygen has been consumed by microbes, corrosion of the container due to pitting and uniform corrosion has stopped.

- The porewater in the sealing material (and in the buffer) becomes more saline due to the ingress of groundwater that mixes with the starting porewater.

- The fuel remains intact. The buildup of He from alpha decay increases the internal pressure; however this pressure is well within the structural resistance of the cladding. 


\subsection{Uncertainties in the base scenario}

Each element of the above base case scenario is subject to a relative degree of confidence, depending on the current state of knowledge. According to McMurry et al. (2003), many elements related to coupled THMC processes represent uncertainties in the base case scenario and need to be better understood. These authors recommend the following:

- The evolution of the temperature field has traditionally been calculated with pure thermal models. There is a need to confirm the thermal results with coupled THM models.

- The anticipated loads on the container due to buffer swelling are expected to be nonuniform, but there is only limited analysis on both the nature of these non-uniform loads and their effect on the container's longevity.

- The nature and extent of initial buffer shrinkage and cracking due to heating is not yet well characterized.

- Swelling characteristics of a wide range of bentonite-based buffer have been relatively well studied in the laboratory, but need to be confirmed for site-specific conditions.

- The saturation rate of the repository has to be confirmed for site specific conditions using coupled THM models. (For example Millard et al. 2005 has shown that the saturation rate is largely dependent on the permeability and the degree of fracturing of the rock mass. The time for full resaturation of a repository varies between 10 to 1000 years depending on the rock permeability).

- Fracture development in the geosphere around the repository has to be better quantified including site-specific conditions. 


\section{Proposed work in task A}

Task A of the DECOVALEX-THMC project shows an example of how the consideration of coupled THM processes can be used to address uncertainties related to SA. Cooperation between geoscientists of different specialties and SA analysts is strongly desirable at all stages of a repository planning and development, and would provide additional confidence in SA results.

Task A is divided into the following subtasks:

1. Preliminary THM analysis of the near field (subtask A-1): develop a preliminary THM model of the near field of the repository, including one horizontal emplacement borehole and one pillar and perform one set of preliminary calculations. Many properties of the geological and engineered barriers needed for coupled THM modelling have to be assumed at this stage without a systematic calibration. The purpose of subtask A1 is to familiarize the modellers with the problem, and also to identify areas which need more model development and calibration.

2. Model development and calibration (subtask A-2): this phase is necessary to fine tune our models and tools (THM computer codes) and build confidence in these tools. The following areas of concern were identified by McMurry et al. (2003) and also from subtask A-1:

a. Development of THM models of the rock, taking into account damage mechanics. Laboratory experiments and in-situ experiments are available to calibrate the model. Of concern are the strength criteria, and the change in elastic parameters and permeability and the onset of crack propagation. 
b. Calibration of THM model for MX-80 bentonite with available laboratory experiments.

3. Final THM analysis of the near field (subtask A-3): The safety indicators would be: temperature, damage zone determination, change in permeability, re-saturation of the engineered barriers, swelling stresses, and perturbation in the hydraulic head distribution. These indicators will be the output required from the research teams and would be communicated to the SA analysts. The analysis would be performed for a period of one thousand years and would include the following phases: excavation and waste emplacement (years 0-30); observation and monitoring period (years 30-100) and postclosure period (years 100- at least 1000).

Communication between the THM modellers, the SA analysts and the experimentalists is promoted during the whole project. In particular, at the end of subtask 3, the results of the THM analyses would be communicated to the SA analyst, who would provide feedback on how the SA results could be affected, or if necessary, would perform a revised SA.

Subtask A-2 pertaining to the model development and calibration of the granite and bentonite behaviour, both from laboratory and in-situ tests are presented by Chijimatsu et al (2008), Nguyen (2007) and Rutqvist et al. (2008). In the remaining part of this paper, we will present the results of subtask A-1, preliminary modelling followed by A-3, final modelling, of coupled THM processes in the near field of a horizontal borehole disposal concept in the Canadian Shield. 


\section{Modelling of THM processes in the near field of a horizontal borehole disposal concept in the Canadian Shield}

\subsection{Conceptual and mathematical model}

We looked at a horizontal borehole concept, where the waste containers will be emplaced in horizontal galleries. MX-80 bentonite would be the buffer material around the containers. The dimensions and specifications for the horizontal borehole concept are summarized by Nguyen and Jing (2006) and the basic properties of the MX-80 bentonite are given by Borgesson and Hernelind (1999). Assuming repetitive symmetry, one web of the repository is modelled by all teams, as shown in Figure 4. The THM boundary conditions are also illustrated in Figure 4. At a depth of $657 \mathrm{~m}$, the magnitudes of the minor and major principal stresses are assumed to be

respectively 17 and $62 \mathrm{MPa}$. The minor principal stress is vertical, and corresponds to the weight of the overburden. The major principal stress is horizontal, and intentionally oriented in a radial direction to the room. This radial orientation is the most critical and would allow us to study the maximum potential for rock damage around the rooms. 


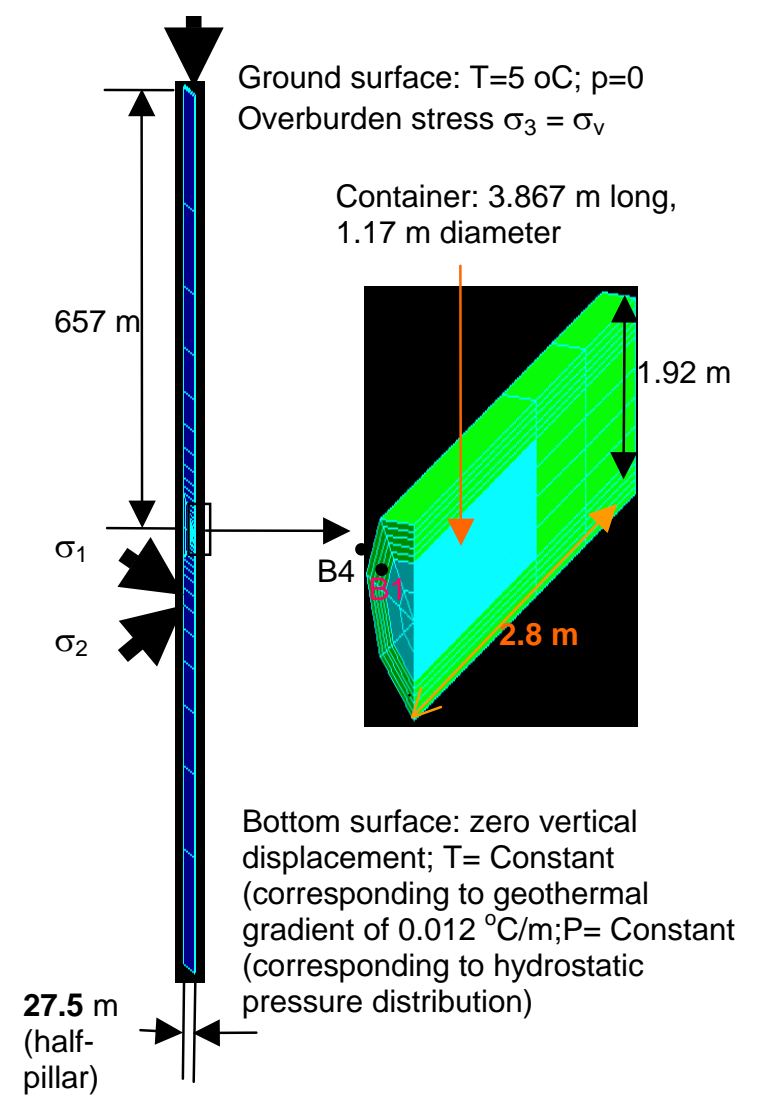

Figure 4. Mathematical model and boundary conditions

In order to simulate the THM response of the host rock, a transient analysis has to be performed by the two teams according to the following sequence:

i) Perform first a steady state HM analysis to establish pre-excavation conditions using the boundary conditions shown in Figure 4.

ii) Perform a transient HM analysis for 30 years to simulate the excavation phase of the repository. The borehole is assumed to be open during that phase, and forced ventilation is assumed to be active in the underground works, resulting in a relative humidity between 50 to 100\% (Figure 5.a). Excavation results in a re-orientation of the stress field, resulting in high 
stress concentration around the borehole. The above factor, combined with some drill and blast effects, would result in an excavation damage zone where the mechanical and hydraulic properties would be modified compared to the original rock conditions. Groundwater would flow towards the borehole; its flow rate is determined not only by hydraulic gradients alone, but also by coupled hydraulic-mechanical processes dictated by the poro-elastic nature of the host rock (Rutqvist et al. 2008)

iii)At time 30 years, for simplification, it is assumed that all boreholes are instantaneously filled with containers and bentonite. The container heat output is consistent with CANDU fuel characteristics (Nguyen and Jing, 2006), and the transient THM analysis is performed for up to 1000 years. Heat will dissipate from the container, resulting in a temperature rise in the near field (Figure 5.a). The temperature gradient will induce outward vapour flow in the bentonite, resulting in drying of the bentonite near the container. The vapour flow is counterbalanced by inward groundwater flow from the surrounding rock. The time for full resaturation of the bentonite is thus depending on the magnitude of these two opposing fluxes. Swelling pressure will develop in the bentonite due to resaturation (Chijimatsu et al. 2008) and will be transmitted to ther container. Thermal stresses would generate in the surrounding rock, possibly inducing an extension of the EDZ. 


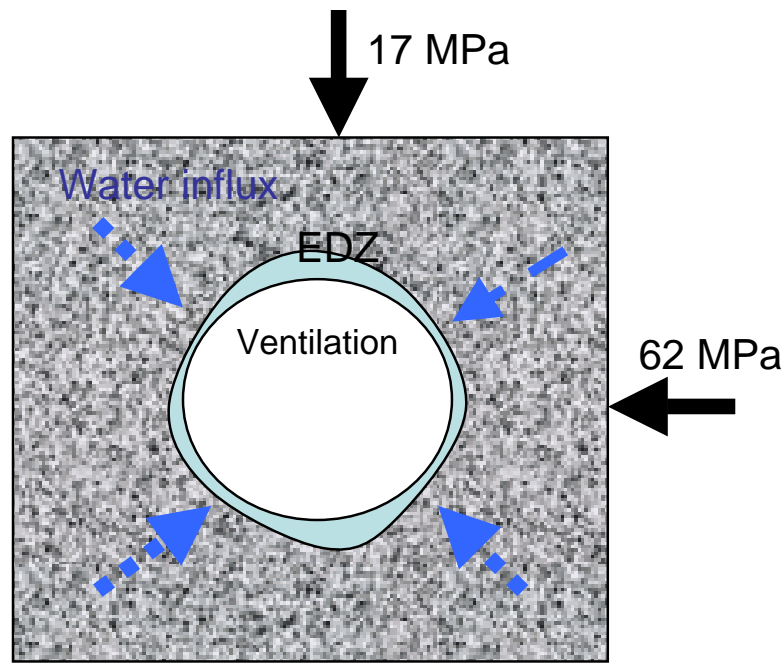

a) Excavation

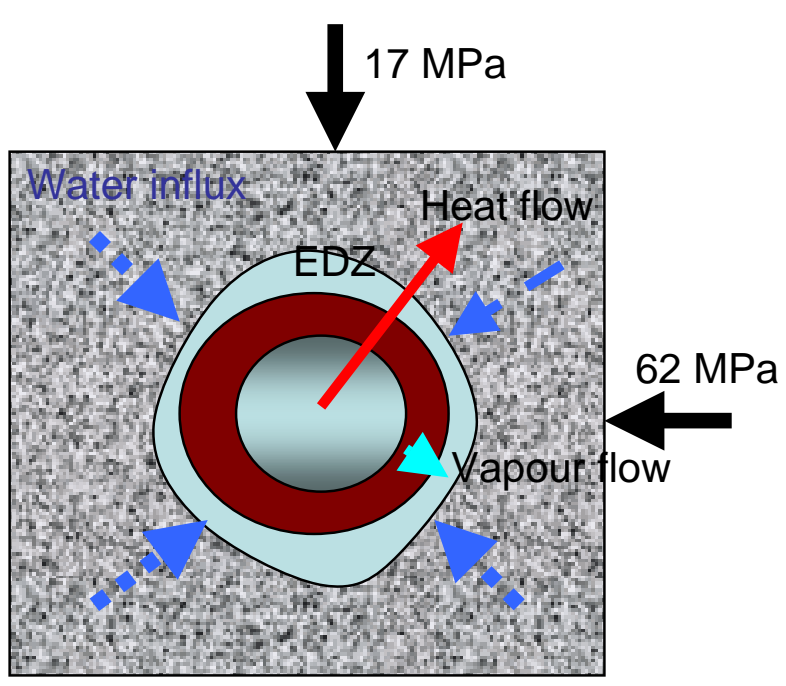

b) Post-emplacement

Figure 5.

THM processes after excavation and emplacement of canister and bentonite.

The mathematical modeling of the processes described above requires a formulation that can simulate interaction between these processes. All the teams used the general framework of Biot's theory of poroelasticity, and modify and extend the governing equations of this framework to include thermal effects, the variable degree of saturation in the bentonite and also vapour flow induced by thermal gradients (Rutqvist et al. 2005). For example, the CNSC team developed the finite element computer code FRACON that numerically solves the following coupled partial differential equations:

$$
\frac{\partial}{\partial x_{i}}\left(\kappa_{i j} \frac{\partial T}{\partial x_{j}}\right)+q=\rho C \frac{\partial T}{\partial t}
$$




$$
\begin{aligned}
& \frac{\partial}{\partial x_{i}}\left(\frac{\rho_{w} k_{i j} K_{r}}{\mu}\left(\frac{\partial p}{\partial x_{j}}+\rho_{w} g j\right)\right)-\frac{\partial}{\partial x_{i}}\left(D_{T} \frac{\partial T}{\partial x_{i}}\right) \\
& +\rho_{w}\left[G_{s}(1-n) \frac{d w}{d p}\right] \frac{\partial p}{\partial t}+\rho_{w}\left[\frac{-n S}{K_{w}}+S\left(S-G_{s} \frac{w}{n}\right) \frac{n-\alpha}{K_{s}}\right] \frac{\partial p}{\partial t} \\
& +\rho_{w}(S \alpha) \frac{\partial}{\partial t}\left(\frac{\partial u_{k}}{\partial x_{k}}\right)+\rho_{w} S\left((1-\alpha) \beta-n \beta_{w}-(1-n) \beta_{s}\right) \frac{\partial T}{\partial t}=0 \\
& G \frac{\partial^{2} u_{i}}{\partial x_{j} \partial x_{j}}+(G+\lambda) \frac{\partial^{2} u_{j}}{\partial x_{i} \partial x_{j}}+\alpha S \frac{\partial p}{\partial x_{i}}-\beta K_{D} \frac{\partial T}{\partial x_{i}}+F_{i}=0
\end{aligned}
$$

The primary unknowns of the above equations are: $\mathrm{T}$, temperature; $\mathrm{u}_{\mathrm{i}}$, displacement, and $\mathrm{p}$, pore pressure (tension is positive). These variables are functions of both the spatial variables $\left(\mathrm{x}_{\mathrm{i}}\right)$ and time (t). A summary of the meaning and hypotheses used for each equation is given as follows:

a) equation of heat conservation :

Equation (1) is the equation of conservation of heat, where heat conduction is assumed to be the only mechanism of heat transport. In this equation, $\kappa_{i j}$ is the thermal conductivity tensor $(\mathrm{W} / \mathrm{m}$ $\left./{ }^{0} \mathrm{C}\right), \rho$ is the density of the bulk medium $\left(\mathrm{kg} / \mathrm{m}^{3}\right), C$ is the bulk specific heat of the medium $\left(\mathrm{J} / \mathrm{kg} /{ }^{0} \mathrm{C}\right)$ and $q$ accounts for distributed heat generation in the poroelastic medium $\left(\mathrm{W} / \mathrm{m}^{3}\right)$.

b) equation of pore water flow:

Equation (2) is the equation of pore water flow in the saturated-unsaturated porous medium, derived from considerations of mass conservation.

- The first term of the equation results from a generalization of Darcy=s law of water flow in variably saturated porous media. In this term, $\mathrm{k}_{\mathrm{ij}}$ is the saturated permeability tensor $\left(\mathrm{m}^{2}\right) ; \mathrm{K}_{\mathrm{r}}$ ( non-dimensional) is the relative permeability of unsaturated media and is a function of the degree of saturation $S$ (For $\left.S=1, K_{r}=1\right) ; \mu(\mathrm{kg} / \mathrm{m} / \mathrm{s}$ ) is the viscosity of water, $\rho_{\mathrm{w}}$ is the density of water, which are both functions of temperature.

- The second term represents vapor flow due to thermal gradients. In this term $\mathrm{D}_{\mathrm{T}}\left(\mathrm{m}^{2} / \mathrm{s}\right)$ is the coefficient of thermal vapour diffusivity

- The third term represents water retention due to the unsaturated state of the medium .In this term, $\mathrm{w}$ is the gravimetric water content, $\mathrm{n}$ is the porosity and $G_{s}$ is the specific gravity of the solid particles. When the medium is fully saturated, $\mathrm{w}$ is independent of $\mathrm{p}$ 
and this term becomes zero.

- The fourth term represents water retention due to compressibility of the water and the solid phase, where $1 / K_{w}$ is the coefficient of compressibility of water $\left(\mathrm{Pa}^{-1}\right)$ and $1 / K_{\mathrm{s}}$ is the coefficient of compressibility of the solid phase $\left(\mathrm{Pa}^{-1}\right)$

- The fifth term represents water retention due to the consolidation of the porous medium

- The sixth term represents water flow due to the difference in thermal expansion between the water and the solid material, where $\beta_{\mathrm{w}}$ and $\beta_{\mathrm{s}}\left(1 /{ }^{\circ} \mathrm{C}\right)$ are the coefficient of volumetric thermal expansion of the water of the solid material, respectively.

c) Equation of equilibrium:

Equation (3) is the equation of equilibrium of the porous medium. In this equation, $\mathrm{G}(\mathrm{Pa})$ and $\lambda$ (Pa) are Lame's constants of elasticity and $\beta$ is the coefficient of volumetric thermal expansion of the solid matrix. $G$ and $\lambda$ can also be expressed as functions of the more commonly used Young's modulus E (Pa) and Poisson's ratio $v$ (non-dimensional). $\alpha$ is Biot-Willis' coefficient of poroelasticity.

In the preliminary modelling performed in subtask A-1, all research teams assumed that the rock mass is linearly elastic, consequently E, $v$ and $\alpha$ are constant. The degree of damage in the rock is then subsequently assessed by comparing the calculated stresses with a given damage criterion.

The mechanical behaviour of the bentonite, on the other hand, is strongly dependent on its saturation characteristics. All teams adopted a nonlinear elastic formulation that takes into account that dependency. For example, the CNSC team used a state-surface approach to express the coefficients E, $v$ and $\alpha$ as function of suction and void ratio (Nguyen et al. 2005).

Basic average properties of the rock mass and the bentonite have been measured in laboratory and/or in-situ experiments and are given below.

Rock mass basic properties (at $650 \mathrm{~m}$ depth)

Density (kg/m3): 2650

Young's modulus (GPa): 60

Poisson’s ratio: 0.202

Biot's coefficient: 0.3 
Coefficient of linear thermal expansion $\left({ }^{\circ} \mathrm{C}\right): 10 \mathrm{x} 10-6$

Thermal conductivity $\left(\mathrm{W} / \mathrm{m}^{\circ} \mathrm{C}\right): 3$

Permeability $\left(\mathrm{m}^{2}\right): 7 \times 10^{-19}$

Buffer properties

Density $\left(\mathrm{kg} / \mathrm{m}^{3}\right): 1600$ (dry), 1850 (as-placed)

As-placed saturation(\%): 60

Gravimetric moisture content (\%): 16 (as-placed), 26 (saturated)

Thermal conductivity $\left(\mathrm{W} / \mathrm{m}^{\circ} \mathrm{C}\right): 0.4$ (dry), 1.25 (saturated)

Specific heat $\left(\mathrm{kJ} / \mathrm{kg}^{\circ} \mathrm{C}\right): 0.8$ (dry)

\subsection{Preliminary modeling results}

The above basic average properties of the rock mass and the bentonite were determined from laboratory and field tests. However, many other input properties required by coupled THMC modeling, such as thermal vapour diffusivity, swelling characteristics of the bentonite, or rock mass damage criterion are not readily available. In order to harmonize the teams' work, the following input characteristics of the rock mass were used by all teams in the preliminary modeling. The input properties for the bentonite are on the other hand strongly dependent on the particular model used by each team; consequently, the selection of the input parameters was left to the teams' choice, based on past experience with similar projects.

\section{$\underline{\text { Rock mass failure criterion }}$}

The Hoek and Brown's failure criterion, expressed in term of effective stress:

$$
\sigma_{1 f}^{\prime}=\sigma_{3}^{\prime}+\sqrt{m \sigma_{c} \sigma_{3}^{\prime}+s \sigma_{C}^{2}}
$$

with: 
$\sigma_{\text {if }}^{\prime}=$ major effective principal stress at failure

$\sigma_{3}^{\prime}=$ minor effective principal stress

The effective stress is defined as:

$\sigma_{i j}^{\prime}=\sigma_{i j}-p \delta_{i j}$

with:

$\sigma_{i j}^{\prime}=$ effective stress

$\sigma_{i j}=$ total stress

$\delta_{i j}=$ Kroenecker delta

$=1(i=j)$ and 0 (otherwise)

$p=$ pore pressure

Rock mass permeability function

The rock mass permeability is assumed to be a function of the effective porosity. This function is derived from data derived from laboratory experiments on granite samples with a permeability range of $10^{-19}$ to $10^{-17} \mathrm{~m}^{2}$. The permeability function is shown in figure 6 .

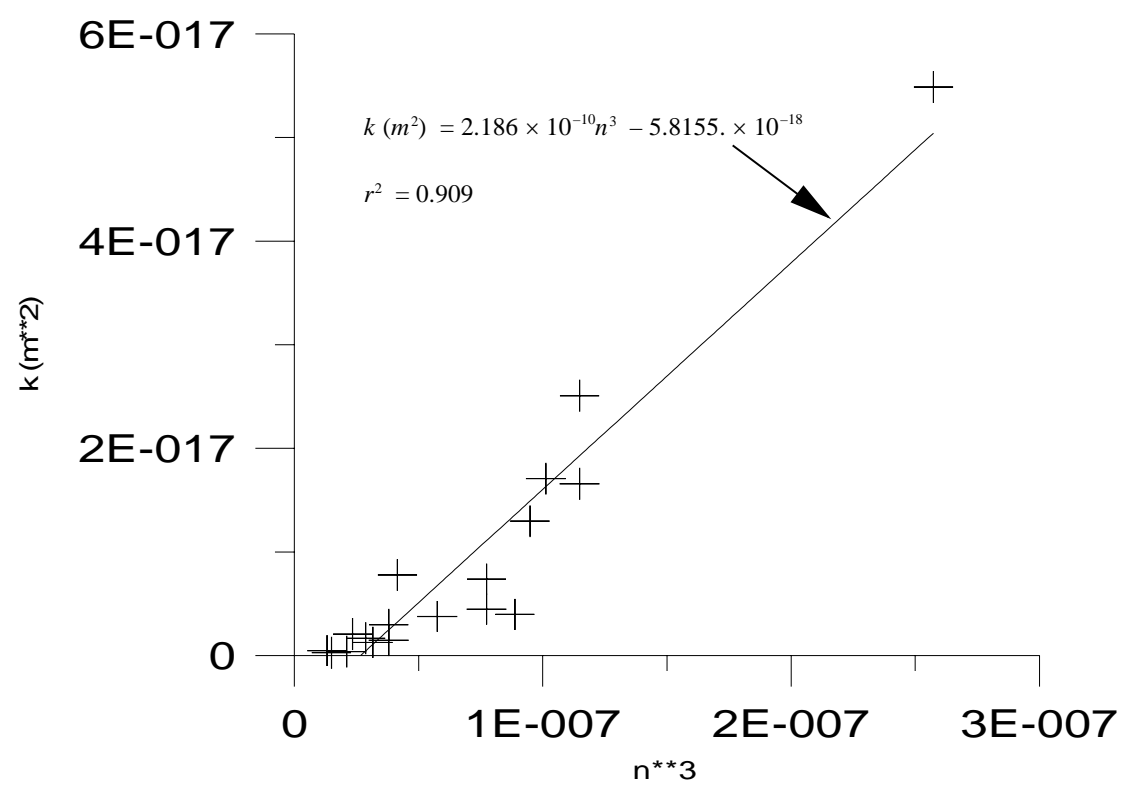

Figure 6. Suggested permeability function for the rock in the preliminary modelling 


\section{Preliminary modeling results}

The maximum temperature developed near the waste canister (point B1 shown in Figure 4) is shown in Figure 7. All teams found that a peak temperature of approximately $60^{\circ} \mathrm{C}$ occurs within 10 years after waste emplacement.

The evolution of the degree of saturation at point B1 in the buffer is shown in Figure 8. All teams found that there is a de-saturation of the buffer near the canister due to vapour flow from the heat source, followed by a re-saturation. Most teams predict that re-saturation would be complete within 10 years after wastes emplacement.

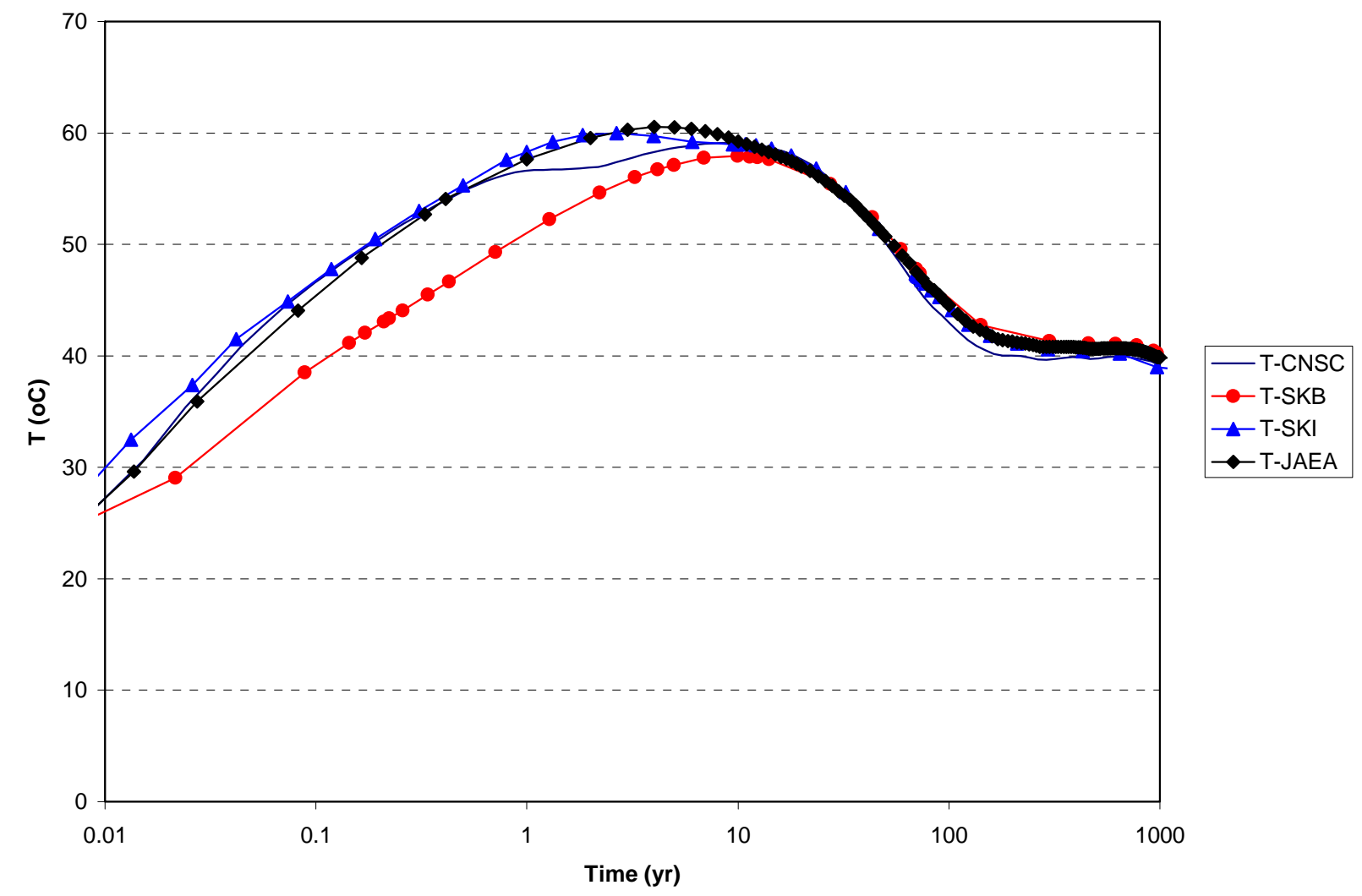

Figure 7. Temperature in buffer at container from preliminary modelling 
The evolution of total stress in the buffer near the canister is shown in Figure 9. The total stress is the sum of pore pressure, swelling pressure and thermal stresses. CNSC, JAEA, SKB and SKI obtained maximum compressive stresses of close to, or marginally above, $15 \mathrm{MPa}$. The CNSC, SKB and JAEA predict that the maximum stress is attained within the first 10 years after wastes emplacement, while SKI predicts a much longer time beyond 1000 years. This difference is due to the predicted time when full resaturation is re-established, as discussed later.

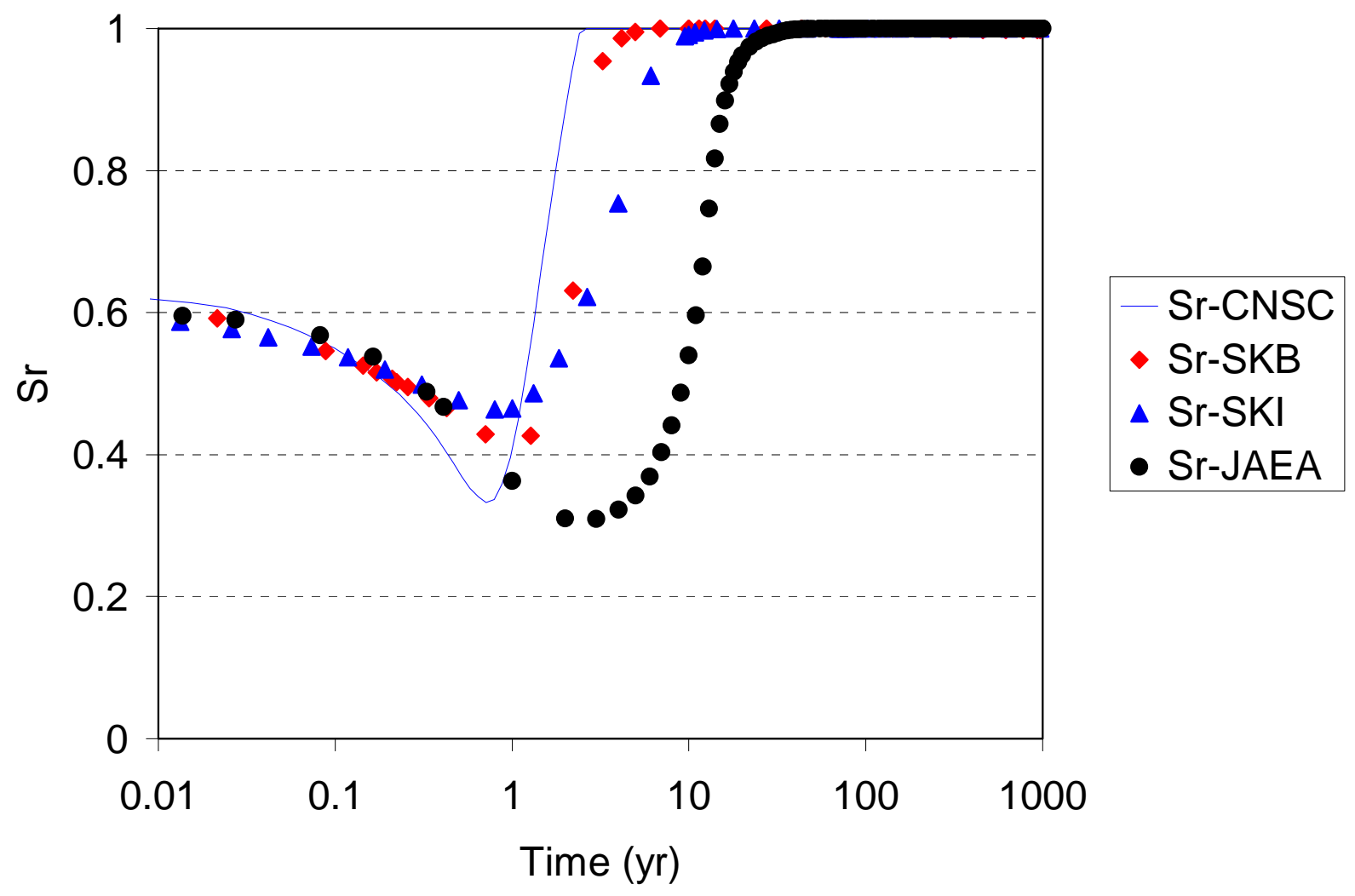

Figure 8. Buffer resaturation at container from preliminary modelling

Most teams predict local failure of the rock mass around the borehole. For example, SKI’s results for effective stress (total stress minus pore pressure) evolution at the top and the side wall of the borehole are illustrated in Figure 10. The stresses at these two points are compared with 
the Hoek-Brown failure criterion. It is shown that at the top of the borehole, failure of the rock can occur right after excavation due to an increase of the major principal stress and a decrease of the minor principal stress. For the point on the side wall, excavation induces a decrease in both minor and major principal stresses. At waste emplacement, these stresses increase due to a combination of buffer swelling and thermal effects. However, when the hydrostatic pressure gradually re-establishes, these stresses decrease again, and failure in tension is predicted within 1000 years after wastes emplacement.

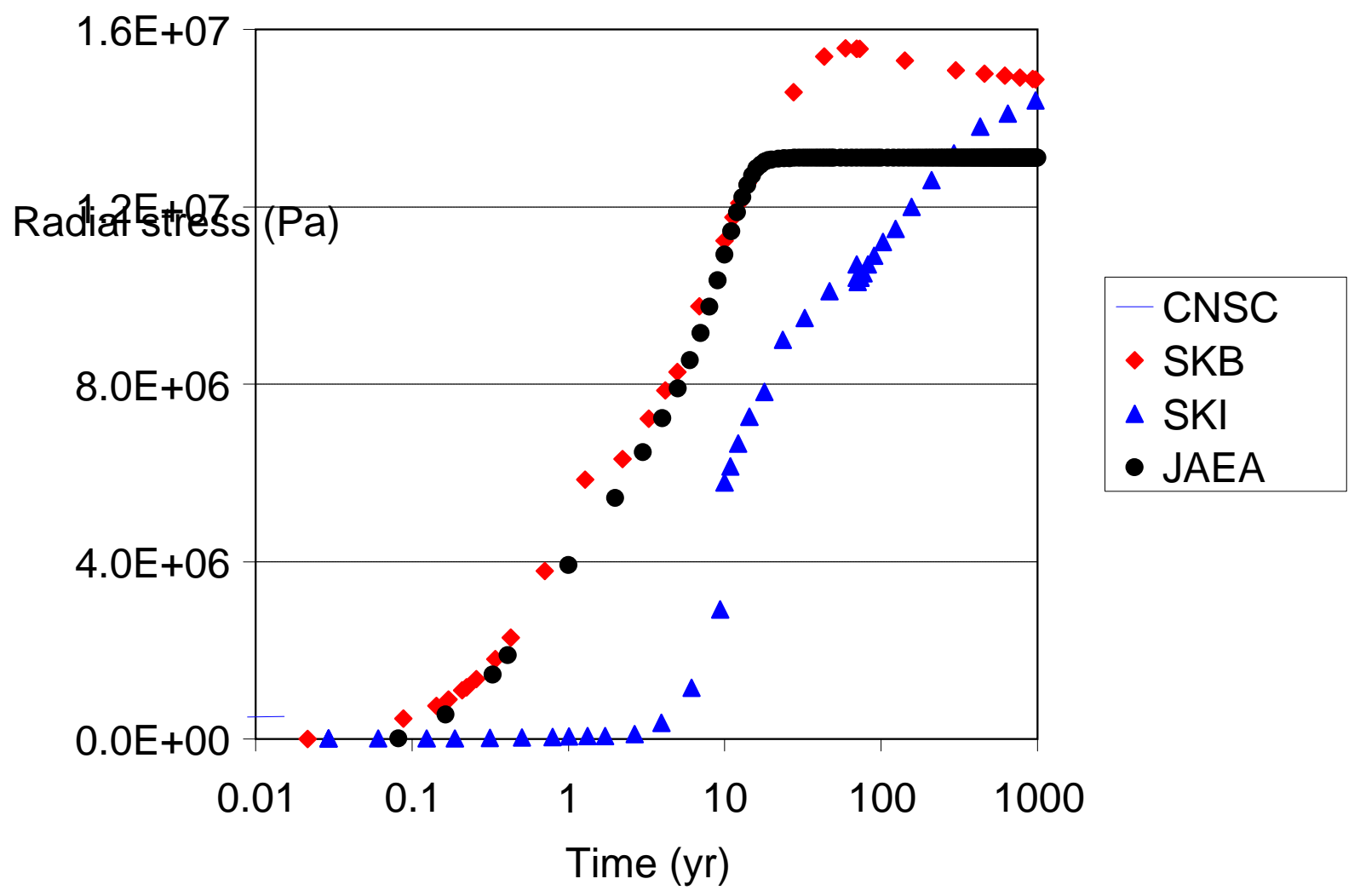

Figure 9. Total stress in buffer from preliminary modelling 


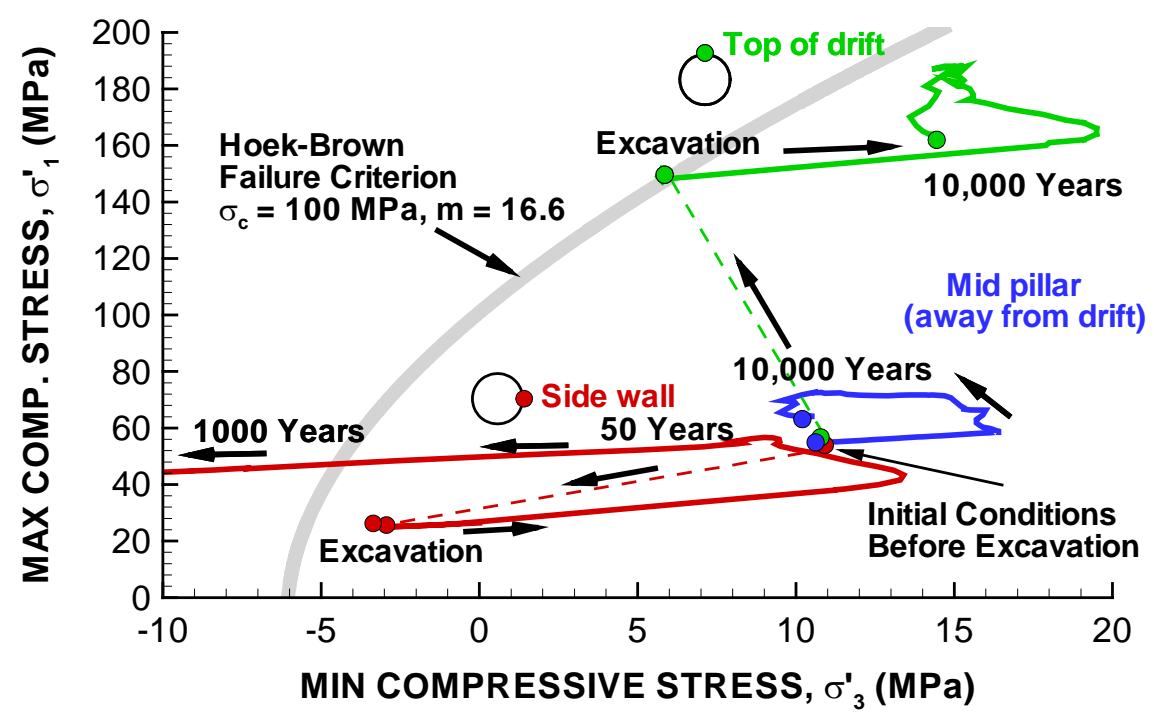

Figure 10. Effective stress evolution and failure conditions around the drift from preliminary modelling (SKI results)
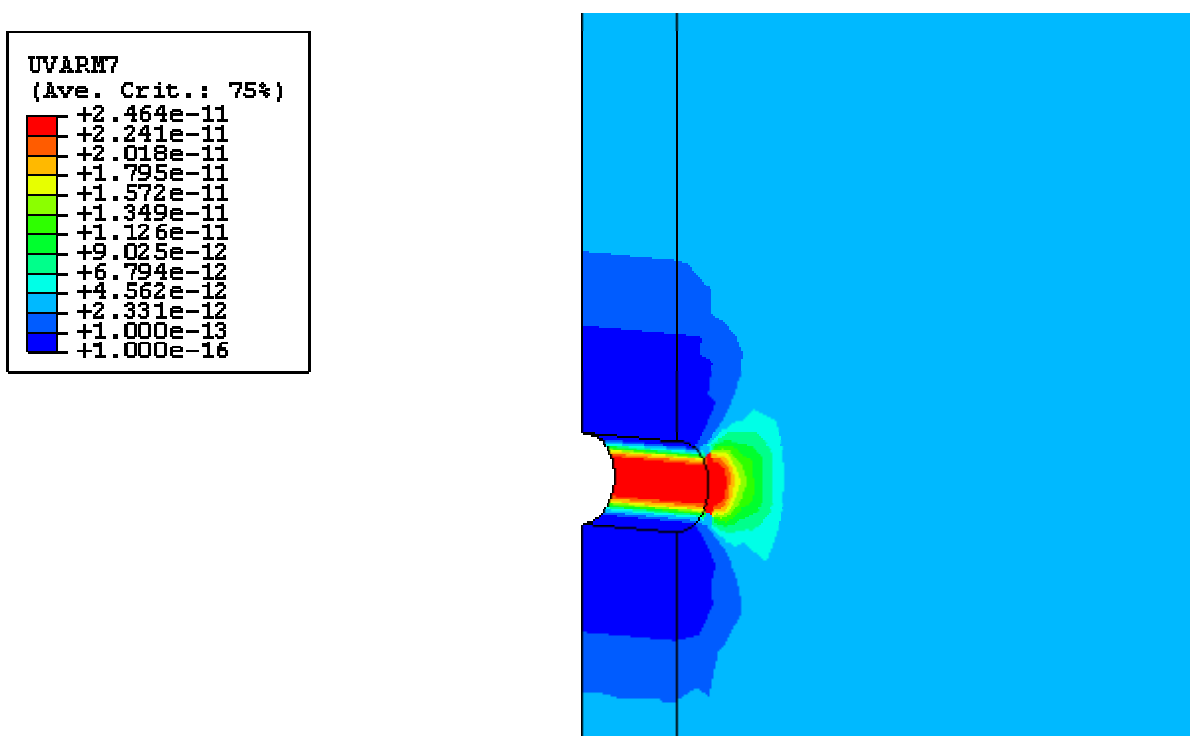

Figure 11. Permeability $(\mathrm{m} / \mathrm{s})$ of rock mass 70 years after waste emplacement from preliminary modeling (from SKB)

The change in the stress regime would change the permeability in the rock mass. For example, as shown in Figure 11, SKB predicted that due to an increase in the mean stress, a practically impermeable zone is formed at 70 years on the top and bottom of the drift. On the other hand, 
due to stress decrease, the sides of the drift would experience an increase of permeability by one order of magnitude. These results do not agree with experimental observations from in-situ excavation experiments, such as the one performed at the TSX tunnel of the Underground Research Laboratory (URL) in Manitoba, Canada (Rutqvist et al. 2008). This disagreement points to the need to refine constitutive relationships in order to better predict the extent and characteristics of the damage zone, as will be discussed later in this paper.

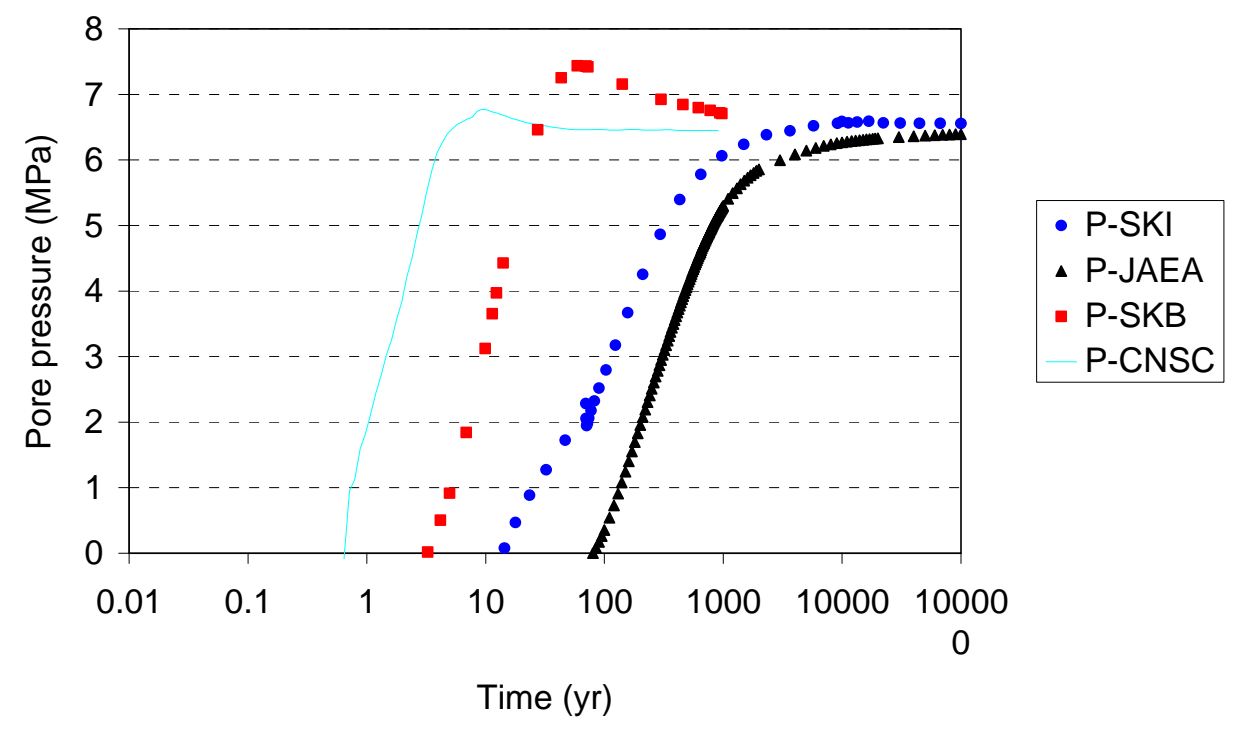

Figure 12. Pore pressure evolution in rock mass near buffer on side wall.

The predicted time when full hydrostatic pressure is re-established at the repository level depends on the assumed permeability function for the rock used by the different teams. It also depends on whether the team assumed an initial relative humidity of $100 \%$ or less in the borehole during the 30 years operational period of the repository. Assuming a 50\% relative humidity would induce de-saturation of the rock mass during that period and subsequently, a full hydrostatic re-establishment of the water pressure would take longer. The results for pore pressure evolution at point B4 (indicated on Figure 4) in the rock mass are compared in Figure 
12. It is shown that SKI and JAEA predict a longer period for full restoration of the hydrostatic stress as compared to CNSC and SKB.

\subsection{Final THM modeling}

The purpose of the preliminary THM modelling is to have an initial appreciation of the phenomena and properties that must be better understood in subsequent phases. Many assumptions were introduced for the properties of both the rock mass and bentonite, and these need to be verified and adjusted during the calibration performed in subtask A-2. The following particular points of concern were identified from subtask A-1, addressed in subtask A-2 and taken into account in subtask A-3:

1. Some teams predicted that the maximum total stress in the MX-80 bentonite could slightly exceed the 15 MPa design pressure for the container. The MX-80 bentonite exhibits very nonlinear THM behaviour and small variations in the assumed input properties could significantly influence the results. A systematic model calibration with laboratory data was performed in order to predict stresses in the bentonite with more confidence (Chijimatsu et al. 2008). As a result of that calibration, it was found that most of the THM properties of the bentonite assumed in the preliminary modelling need only slight adjustment, however the coefficient of thermal vapour diffusivity is still uncertain. That coefficient should be varied in the final models in a parametric study.

2. The preliminary results show that a damage zone could be formed around the waste emplacement boreholes; the extent of this damage zone, as well as its hydraulic and mechanical properties, should be better predicted. The teams refined constitutive relationships for the prediction of rock damage using laboratory and in-situ experimental data (Nguyen et al. 2007; Rutqvist et al. 2008). The main conclusion is that other criteria 
for rock damage were more appropriate than the Hoek and Brown criterion used in subtask A-1. The SKI team also recommends that the effects of drill and blast should be considered.

3. The variation of rock permeability with stress or strain could have significant effects on the re-saturation time of the bentonite. Permeability functions specific to the granite under consideration were developed using in-situ experimental data (Rutqvist et al. 2008). As a result, permeability functions of both deviatoric and mean stresses are recommended and should be used instead of the one shown in Figure 6. It was also found that around the TSX tunnel of the URL in Manitoba, outside of the excavation damage zone, the permeability of the granite is typical of intact rock, of the order of $10^{-21} \mathrm{~m}^{2}$. This is two orders of magnitude lower than the average permeability used in the preliminary model. As a consequence, the SKI team varied the ambient value of permeability in a parametric study.

Two teams, SKI and JAEA, performed the final simulation. The JAEA team used the same permeability function for the rock mass as the one used in the preliminary modelling but a different damage criterion in the final modelling. They did not find substantial differences between the final thermal and hydraulic response of the bentonite in the final modelling results as compared to the preliminary ones. The SKI team thoroughly explored the influence of the rock mass permeability, the thermal vapour diffusivity and the refined constitutive relationships for rock damage on all aspects of the THM response as follows. 


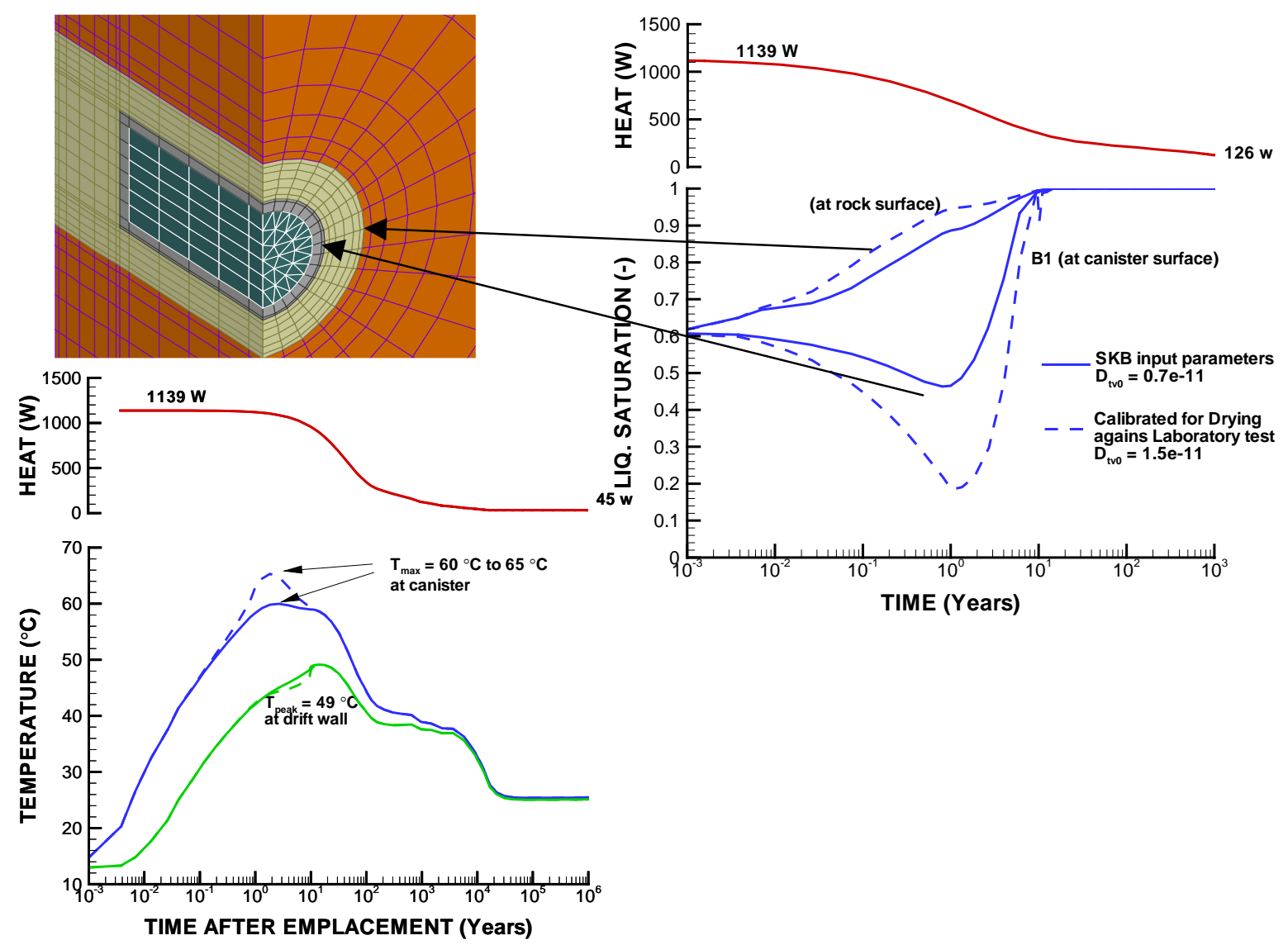

Figure 13. Comparison of SKI final and preliminary results for Temperature and Saturation in the bentonite - Effect of high thermal vapour diffusivity. The dotted lines represent the final results while the solid lines are the preliminary ones.

Figure 13 shows the effects of increasing the coefficient of thermal vapour diffusivity by a factor of two, as compared to the value assumed in the preliminary modelling. This results in a more pronounced drying of the bentonite near the canister in the first year following emplacement; however, the time for full resaturation remains approximately the same at 10 years. The maximum temperature adjacent to the canister increases from 60 to $65^{\circ} \mathrm{C}$, however from a safety perspective, this is largely below the target maximum of $100{ }^{\circ} \mathrm{C}$. Figure 14 shows the combined effects of having both a high coefficient of thermal vapour diffusivity and a low rock mass permeability. The maximum temperature increases more substantially to $75^{\circ} \mathrm{C}$, however it still remains substantially below $100{ }^{\circ} \mathrm{C}$. At 10000 years after emplacement, the bentonite is found to 
be still unsaturated, and the model also indicates de-saturation of the rock mass near the walls of the boreholes.

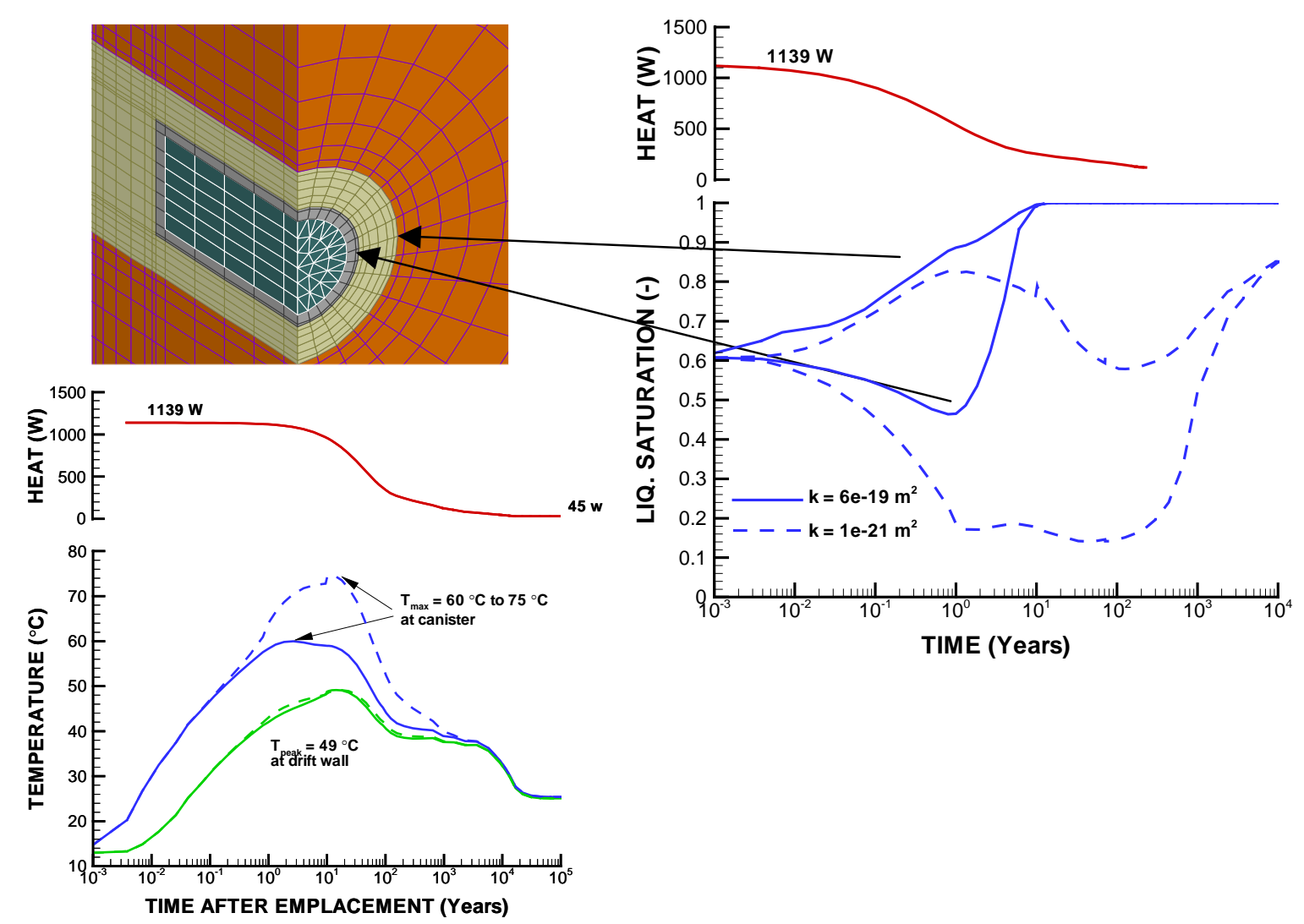

Figure 14. Comparison of SKI final and preliminary results for Temperature and Saturation in the bentonite - Effect of high thermal vapour diffusivity and low rock permeability - The dotted lines represent the final results while the solid lines are the preliminary ones.

Figure 15 compares the maximum stress developed in the buffer around the container for two cases: average rock permeability as in subtask A-1 combined with a high thermal vapour diffusivity, and low rock permeability combined with a high thermal vapour diffusivity. It is seen that in the first case, a maximum total stress of over $15 \mathrm{MPa}$ could develop within a few hundred years after emplacement. This result is similar to the one from subtask A-1; from a safety point 
of view, this total stress exceeds the design load to the container. When the permeability of the rock mass is low, it is predicted that full re-saturation would not occur in 10000 years after emplacement. Consequently, swelling stress could not fully develop, and the total stress remains below $15 \mathrm{MPa}$ during that period of time. In all cases, the calculated stresses are practically uniform around the container, and there would not be any asymmetry of the load provided that the bentonite is homogeneous and uniformly emplaced.

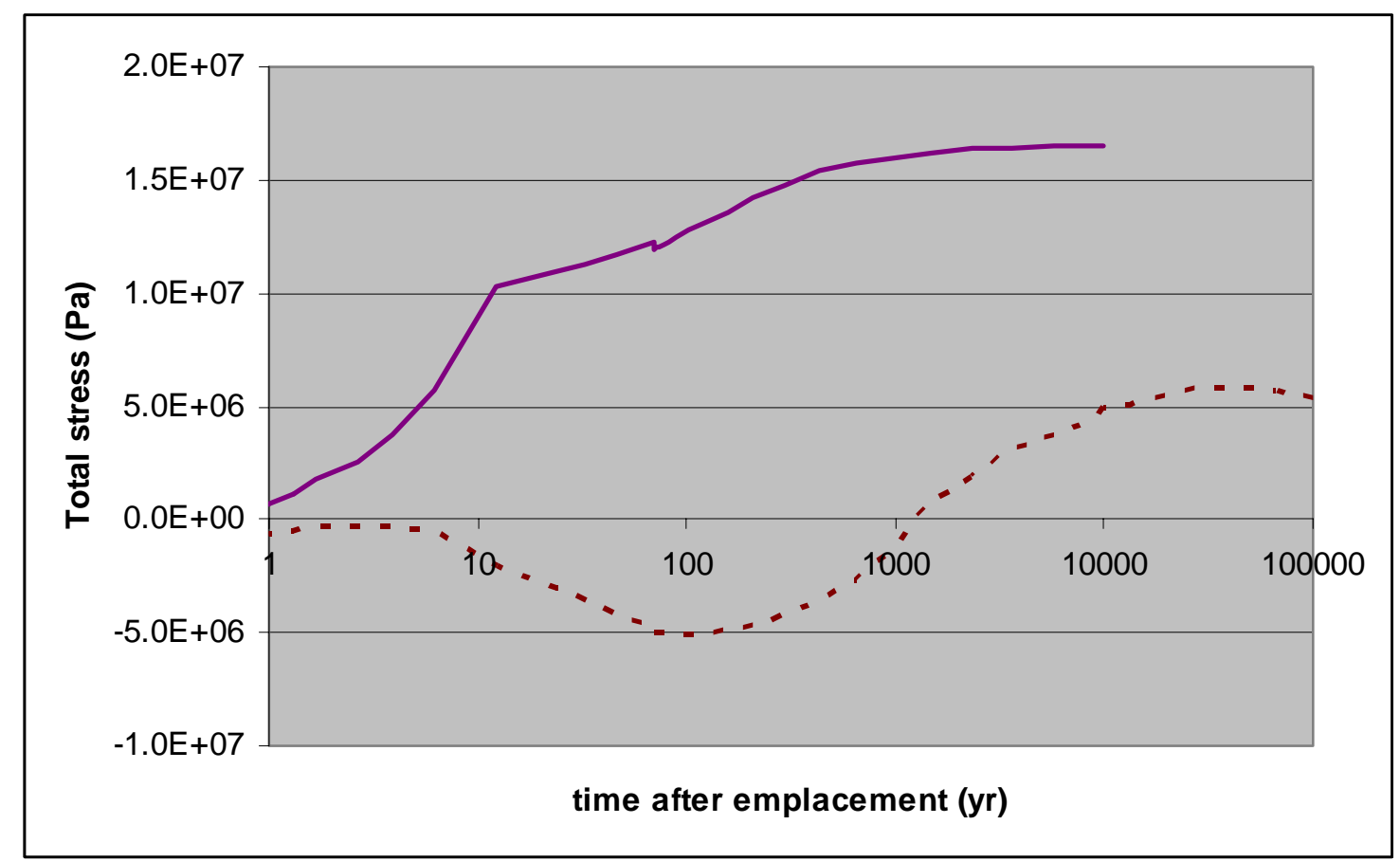

Figure 15. SKI's final prediction of total stress developed on the container - The solid line shows the results when the permeability on the rock is the same as in subtask A-1; the dotted line shows the case of a low rock permeability.

Figure 16 shows the permeability change around the borehole after excavation and in the long term after emplacement of the container and bentonite. Figure 16 shows the case when the rock ambient value of permeability is low $\left(10^{-21} \mathrm{~m}^{2}\right)$. Using the calibrated permeability reported by 
Rutqvist et al. (2008), it is shown that at excavation an inner damage zone of thickness of a few tens of $\mathrm{cm}$ would form at the roof and floor of the borehole, resulting in a 7 to 8 order of magnitude increase in permeability. That inner damage zone would be possibly characterized by spalling and visible fracturing. An outer damage zone would also be formed, extending by a few $\mathrm{m}$ from the walls of the borehole. Although no visible fracturing would be observed for that zone, it is predicted that increase in permeability by up to 6 orders of magnitude would occur. Due to thermal effects, both inner and outer damage zones are predicted to increase in thickness in the long term after waste and bentonite emplacement. The shape of the inner and outer damage zones and the induced permeability distribution shown in figure 16 are considered to be more reliable than the ones shown from the preliminary modeling (for example figure 11), since the predictions are based on constitutive relationships which were derived from a much better understanding derived from laboratory and in-situ experimental data. 

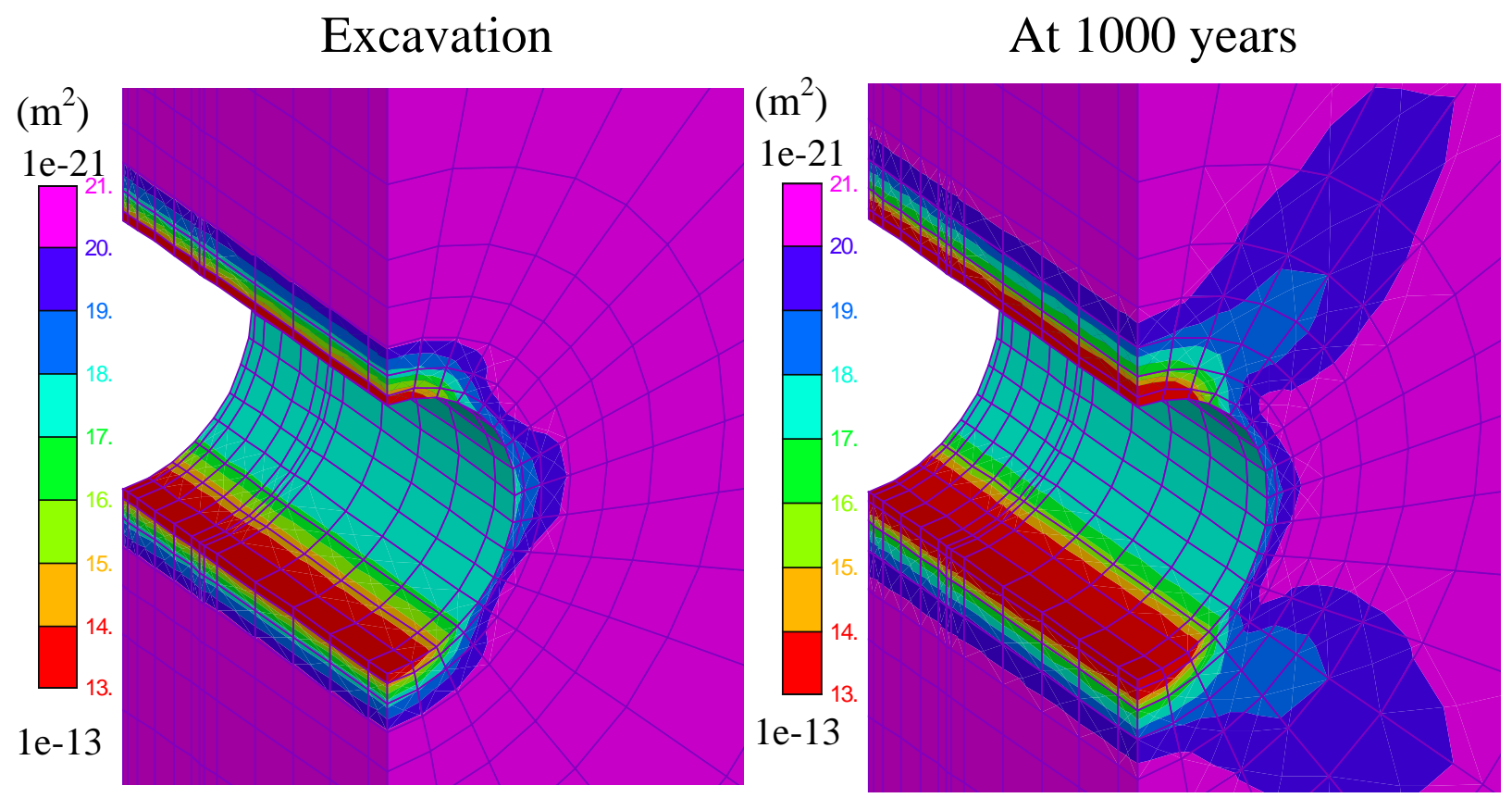

Figure 16. SKI's final results for the evolution of rock damage

\section{Conclusion}

The ultimate objective of any research program related to geological disposal of nuclear wastes should be to provide additional confidence on the long term performance of the repository. In the international DECOVALEX-THMC project, researchers have been developing coupled THMC mathematical models in order to predict the long term evolution of the repository for different scenarios. The results of these predictions should be communicated to the SA analysts so that they can be considered in system models for predicting the overall performance of the repository. In this paper we presented the definition of Task A of the project which is a working example of how interaction between THMC modelling and SA analysis could be performed. We presented 
results of preliminary THM calculations by the teams involved in the project. The purpose of the preliminary THM modelling is to have an initial appreciation of the phenomena and properties that must be better understood in subsequent phases. A final THM modelling was performed after the research teams have performed calibration of their models with in-situ and laboratory experiments. The results of the final modelling are shown and compared to the ones from the preliminary modelling. It was found that the permeability of the rockmass around the emplacement borehole could play a major role in the THM response in the near field. Average permeability for sparsely fractured granite of the Canadian Shield, at a depth of $650 \mathrm{~m}$ which is considered in this case study, would have average permeability of the order of $10^{-19} \mathrm{~m}^{2}$. However, some borehole could be located in essentially intact rock, with permeability of the order of $10^{-21} \mathrm{~m}^{2}$. Except for the extent and characteristics of the excavation damage zone around the emplacement borehole, both sets of models provide rather consistent results as follows:

1. In the case of sparsely fractured rock, the bentonite was predicted to fully resaturate within a few decades after emplacement. For intact rock, full resaturation might take more than 10000 years.

2. Temperature in all cases remains below $100{ }^{\circ} \mathrm{C}$. In case the rock is sparsely fractured, the maximum temperature will reach $60{ }^{\circ} \mathrm{C}$. In the case of intact rock around the borehole, since the bentonite could remain dry for more than thousands of year, its thermal conductivity remains low, resulting in a lower rate of heat dissipation . Consequently, temperature could increase to $75^{\circ} \mathrm{C}$ for the case of intact rock.

3. The predicted maximum total stress in the MX-80 bentonite could exceed the $15 \mathrm{MPa}$ design pressure for the container, when the rock mass is sparsely fractured. The 
maximum load can develop within a few decades to a few hundreds of years after emplacement. However, for intact rock, since the bentonite remains dry, the swelling pressure does not fully develop. Consequently, the total load on the container would remain below $15 \mathrm{MPa}$ for thousands of years. To be on the safe side, the container should be re-designed to withstand stresses higher than $15 \mathrm{MPa}$, or early failure of the containers should be considered in the overall safety assessment of the repository.

4. The preliminary results show that a damage zone could be formed around the waste emplacement boreholes; the extent of this damage zone, as well as its hydraulic and mechanical properties were considered to be unreliable, because they do not correspond to observations from in-situ tests performed at the Underground Research Laboratory (URL) in Manitoba, Canada. The constitutive relationships used in the final modelling were refined using experimental data from both laboratory and in-situ tests performed at the URL. The final modelling predicts an inner damage zone on the roof and floor of the borehole, where visible fracturing would be observed, and permeability increases of up to 8 orders of magnitude could occur. The thickness of the inner damage zone could reach a few tens of $\mathrm{cm}$. An outer damage zone, with no visible fracturing but with permeability increases by up to 6 orders of magnitude, could form within a few $m$ of the walls of the borehole. Both inner and outer damage zones are predicted to grow with the thermal loading.

5. Both inner and outer damage zones must be considered in the safety assessment of repository. Due to the increase in permeability in these zones, the flow rate and radionuclide mass transfer around the deposition holes would increase. The damage zone has the potential to increase the fluxes of radionuclide from the geosphere; the effect of 
such an increase should be taken into account in the safety assessment and mitigated if necessary by the provision of sealing systems

\section{REFERENCES}

Borgesson, L. \& Hernelind, J. (1999) Coupled thermal-hydro-mechanical calculations of the water saturation phase of a KBS-3 deposition hole-Influence of hydraulic rock properties on the water saturation phase. SKB report TR-99-41, SKB, 10240 Stockholm, Box 5864.

Chijimatsu, M., Nguyen, T.S., Jing, L., De Jonge, J., Kohlmeier, M., Millard, A., Rejeb, A, Rutqvist, J., Souley, M. \& Sugita Y. (2005) Numerical study of the THM effects on the nearfield of a hypothetical nuclear waste repository-BMT1 of the DECOVALEX III project. Part 1: Conceptualization of the problems and summary of results. Int. J. Rock Mech. And Min. Sci. 42 (5-6).

Chijimatsu M and others (2008a) Model development and calibration of the coupled thermal, hydraulic and mechanical phenomena on bentonite. Environmental Geology (this issue).

Garisto, F., Avis, J., Calder, N., Gierszewski, P., Kitson, C., Melnyk, T., Wei, K. \& Wojciechowski, L. (2005) Horizontal borehole concept case Study. OPG, NWMD, 700 University Avenue, Toronto, Ont. Canada M5G 1X6, report 06819-REP-01200-10139-R00

Gierszewski, P., Avis, J., Calder, N., D’Andrea, A., Garisto, F., Kitson, C., Melnyk, T., Wei, K. \& Wojciechowski, L. (2003) Third case study - postclosure safety assessment. OPG, NWMD, 700 University Avenues, Toronto, Ont. Canada M5G 1X6, report 06819-REP-01200-10109R00.

Herget, G. \& Arjang, B. (1990) Update on ground stresses in the Canadian Shield. Proc. Specialty Conf. Stresses in Underground Structures, Ottawa, Canada. CANMET, Canadian Government Publishing Centre Supply and Services, Ottawa, Canada.

McMurry, J., Dixon, D.A., Garroni, J.D. Ikeda, B.M., Stroes-Gascoyne, S., Baumgartner, P. \& Melnyk, T.W. (2003) Evolution of a Canadian deep geologic repository. Base scenario. OPG, NWMD, 700 University Avenues, Toronto, Ont. Canada M5G 1X6, report 06819-REP01200-10092-R00,

Nuclear Energy Agency. (2004) Post-closure safety case for geological repositories. Nuclear Energy Agency ISBN 92-64-02075-6

NEA. 2005. Linkage of geoscientific arguments and evidence in supporting the safety case. Second AMIGO workshop, Toronto, Canada. Nuclear Energy Agency (in press).

Nguyen, T.S. and Jing L. (ed.). (2007) Task A:Influence of coupled THM phenomena on the performance of a spent fuel repository- Report of Task A-1, SKI report 2007:0, SKI, Stockholm, Sweden.

Nguyen, T.S. , Selvadurai, A.P.S. and Armand G. (2005) Modelling the Febex THM experiment using a state surface approach. Int. J. Rock Mech. And Min. Sci. 42 (5-6).

Nguyen, T.S. (2007) Damage of Lac du Bonnet Granite in triaxial tests, Proc. Canadian Geotechnical Conference, OttawaGeo2007.

Rutqvist, J., Borgesson, L., Chijimatsu, M., Fujita, T., Nguyen, T.S. \& Jing, L. (2001) Formulation of thermohydromechanics in partially saturated geological media- general equations and four finite element models. Int. J. Rock Mech. And Min. Sci. 38 (1). 
Rutqvist, J., Borgesson, L., Chijimatsu, M.,J. Hernelind, Jing, L., Kobayashi, A. and Nguyen, T.S. (2008) Modeling of Damage, Permeability Changes and Pressure Responses during Excavation of the TSX Tunnel in Granitic Rock at URL, Canada, this issue.

\section{Acknowledgement and disclaimer}

The authors sincerely thank the funding organizations CNSC, SKI, SKB and STUK for their financial support. The opinions discussed in this paper are the authors' and do not necessarily reflect those of the funding organizations. Funding to the LBNL research team and was provided by the Swedish Nuclear Waste Power Inspectorate (SKI). This work was, in part, supported by the U.S. Dept. of Energy under Contract No. DE-AC02-05CH11231. 